\title{
Initial investigation into the effect of varying parameters in using an Er:YAG laser for the removal of brass-based overpaint from an oilgilded frame
}

DOI:

10.1080/19455224.2019.1706592

\section{Document Version}

Accepted author manuscript

Link to publication record in Manchester Research Explorer

Citation for published version (APA):

Boonrat, P., Dickinson, M., \& Cooper, M. (2020). Initial investigation into the effect of varying parameters in using an Er:YAG laser for the removal of brass-based overpaint from an oilgilded frame. Journal of the Institute of Conservation . https://doi.org/10.1080/19455224.2019.1706592

\section{Published in:}

Journal of the Institute of Conservation

\section{Citing this paper}

Please note that where the full-text provided on Manchester Research Explorer is the Author Accepted Manuscript or Proof version this may differ from the final Published version. If citing, it is advised that you check and use the publisher's definitive version.

\section{General rights}

Copyright and moral rights for the publications made accessible in the Research Explorer are retained by the authors and/or other copyright owners and it is a condition of accessing publications that users recognise and abide by the legal requirements associated with these rights.

\section{Takedown policy}

If you believe that this document breaches copyright please refer to the University of Manchester's Takedown Procedures [http://man.ac.uk/04Y6Bo] or contact uml.scholarlycommunications@manchester.ac.uk providing relevant details, so we can investigate your claim.

\section{OPEN ACCESS}




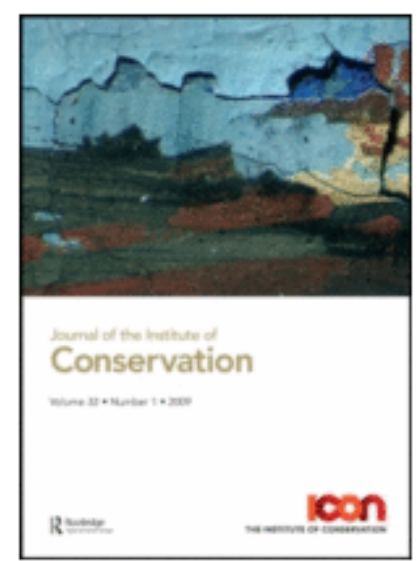

Initial investigation into the effect of varying parameters in using an Er:YAG laser for the removal of brass-based overpaint from an oil-gilded frame

\begin{tabular}{|r|l|}
\hline Journal: & Journal of the Institute of Conservation \\
\hline Manuscript ID & RCON-2019-0024.R1 \\
\hline Manuscript Type: & Original Article \\
\hline Keywords: & laser cleaning, Er:YAG, gilding, discolouration, overpaint, frame \\
\hline \multicolumn{2}{|r}{} \\
\end{tabular}

\section{SCHOLARONE ${ }^{m}$ \\ Manuscripts}


(a)

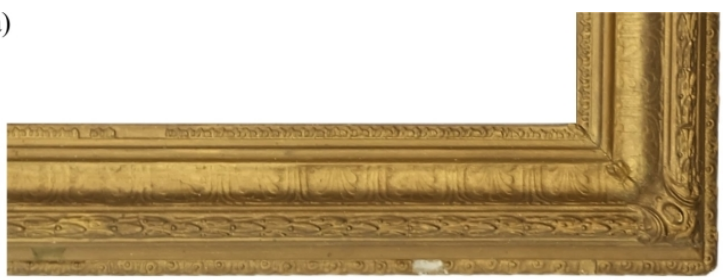

(b)

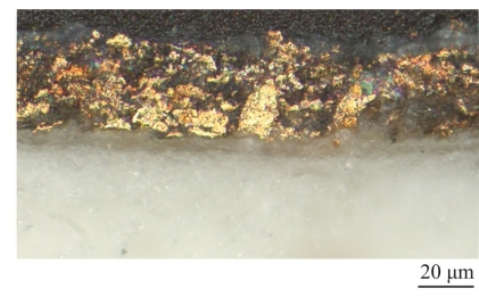

(c)

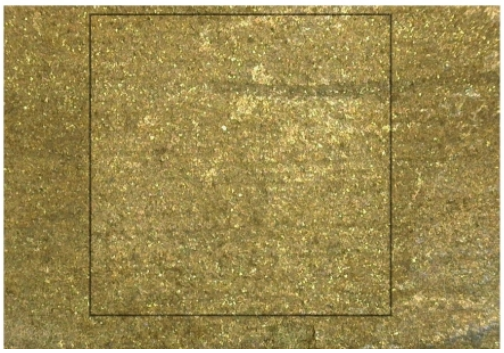

(d)

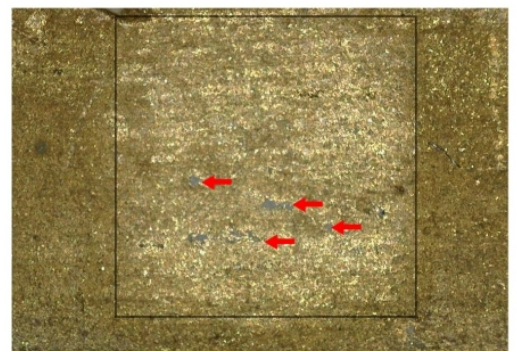

Figure 1 (a) Discoloured brass-based overpaint on the surface of a neoclassical oil-gilded frame. (b) A crosssection, from an area of the frame without remaining gold leaf showing the overpaint layer with thickness 20-40 $\mu \mathrm{m}$. Areas, $1 \mathrm{~cm} \times 1 \mathrm{~cm}$, treated by (c) isopropyl alcohol and (d) acetone. Red arrows indicate small areas of gesso.

$615 \times 329 \mathrm{~mm}(96 \times 96 \mathrm{DPI})$ 
Set Pulse energy $(\mathrm{mJ}) \quad$ Fluence $\left(\mathrm{J} \mathrm{cm}^{-2}\right) \quad$ Pulse duration $(\mu \mathrm{s}) \quad$ Repetition rate $(\mathrm{Hz})$

$\begin{array}{lllll}\text { A } & 15-60 & 0.5-2.1 & 80 & 1 \\ \text { B } & 10-140 & 0.4-5.1 & 120 & 1 \\ \text { C } & 15-60 & 0.5-2.1 & 80 & 1,5 \text { and } 10\end{array}$

Table 1 Sets of laser parameters used to study the effects of Er:YAG radiation on the surface of an overpainted frame 
(a)

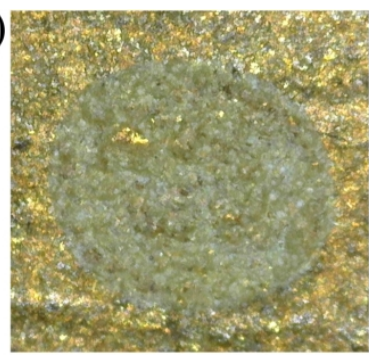

$500 \mu \mathrm{m}$ (b)

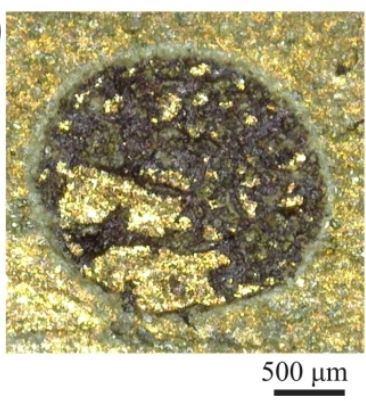

(c)

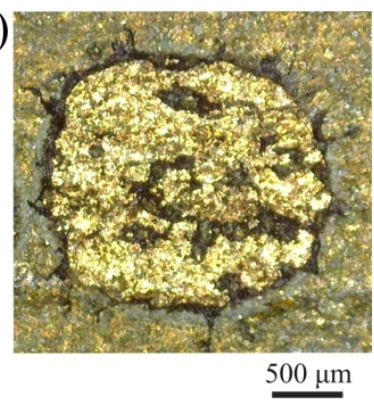

(d)

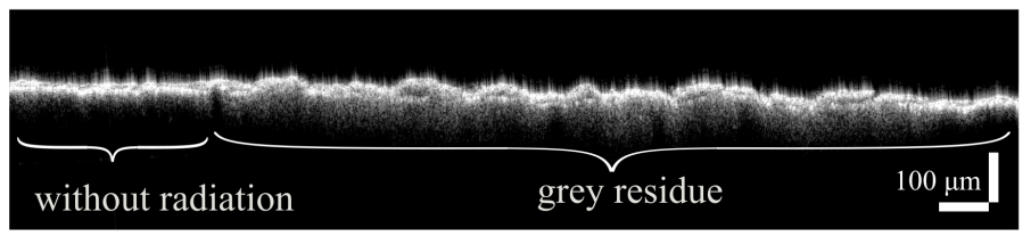

(e)

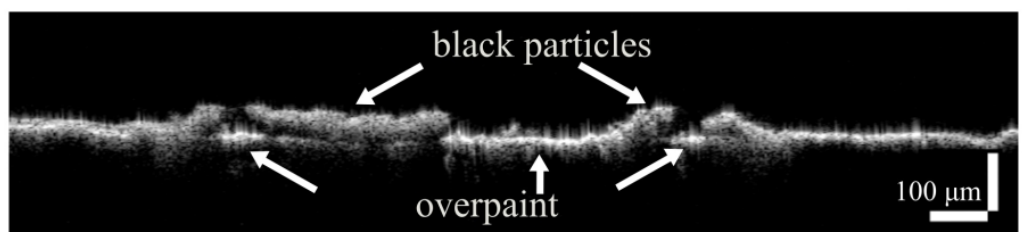

Figure 2 Most irradiated area has the appearance of (a) grey residue, (b) black particles and (c) nondiscoloured overpaint. Cross-section images obtained from optical coherence tomography (OCT): (d) area of frame exposed to a laser pulse $\left(0.5 \mathrm{~J} \mathrm{~cm}^{-2} ; 80 \mu \mathrm{s}\right)$ showing grey residue; (e) area of frame exposed to a laser pulse $\left(1.1 \mathrm{~J} \mathrm{~cm}^{-2} ; 80 \mu \mathrm{s}\right)$ displaying black particles above the overpaint layer.

$$
621 \times 428 \mathrm{~mm}(96 \times 96 \mathrm{DPI})
$$


(a)

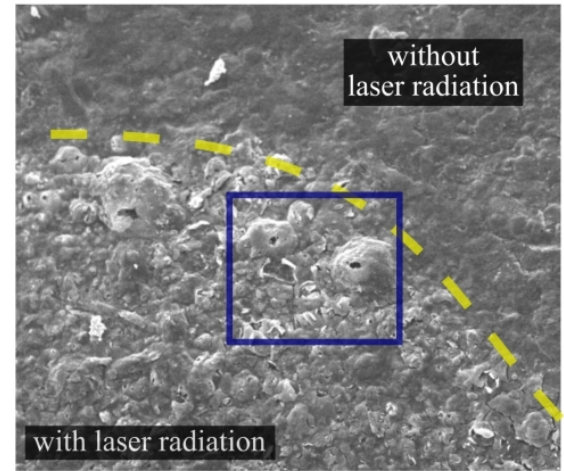

(c)

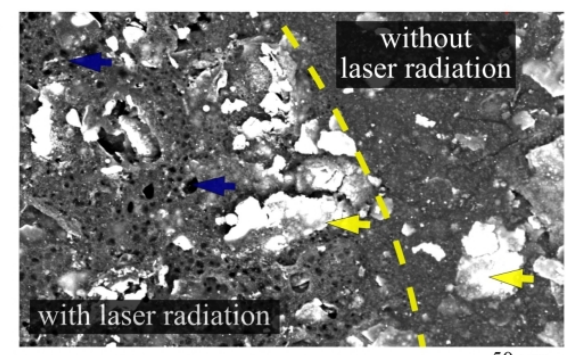

(e) count

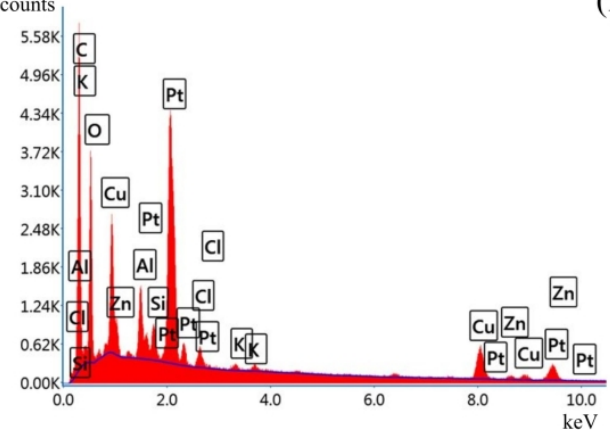

(b)

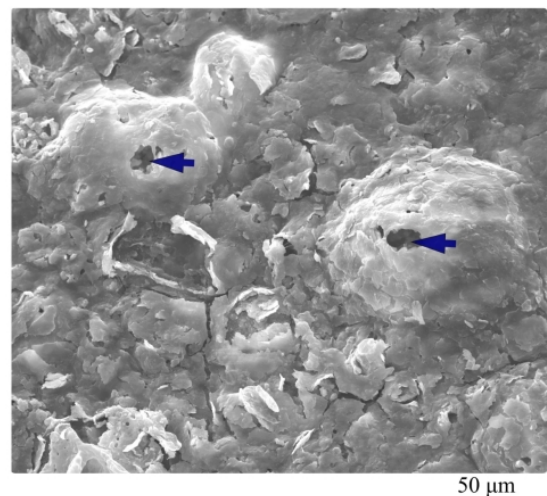

(d)

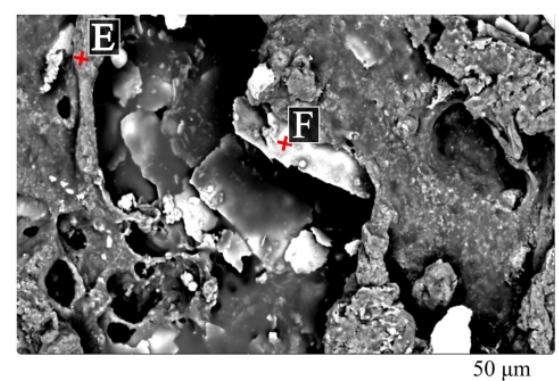

(f) counts

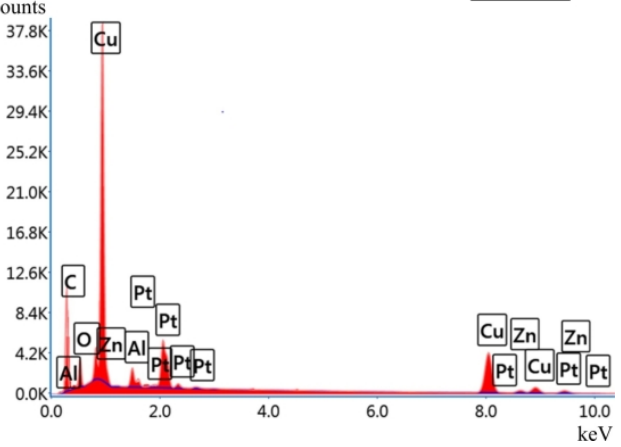

Figure 3 (a) Boundary between area exposed to 10 pulses of $0.5 \mathrm{~J} \mathrm{~cm}^{-2}(80 \mu \mathrm{s} ; 1 \mathrm{~Hz})$, grey residue, and non-irradiated surface. Area in a blue rectangle (b) shows cavitation bubbles with pores (blue arrows). (c)

Boundary between area exposed to 1 pulse of $1.3 \mathrm{~J} \mathrm{~cm}^{-2}(80 \mu \mathrm{s})$ (black particles) and non-irradiated surface; pores (blue arrows), metal flakes (yellow arrows) can be seen. (d) Stacks of brass flakes loosely embedded in a matrix; $E$ and $F$ indicate the location of EDX spot analysis in the matrix and brass flake respectively. (e) EDX spectrum obtained from $E$ (matrix). (f) EDX spectrum obtained from $F$ (brass flake).

$774 \times 790 \mathrm{~mm}(96 \times 96 \mathrm{DPI})$ 
(a)

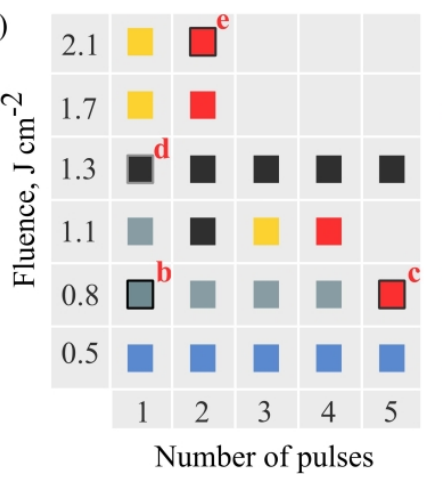

Grey residue

Grey residue with black particles

Black particles

Non-discoloured brass-based overpaint

Exposure of bole or gesso (b)

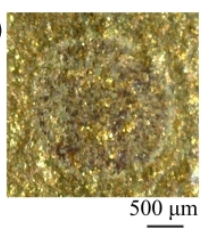

(d)

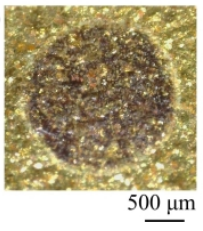

(c)

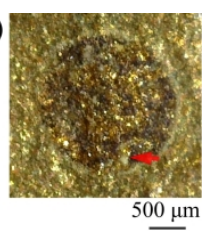

(e)

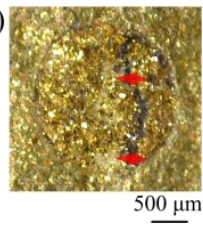

Figure 4 (a) Schematic representation of the effect of fluence and number of pulses delivered to the frame surface. (b-e) Images taken from an optical microscope of irradiated areas with laser parameters labelled in (a). Red arrows indicate spots of gesso.

\section{$1591 \times 563 \mathrm{~mm}(72 \times 72 \mathrm{DPI})$}



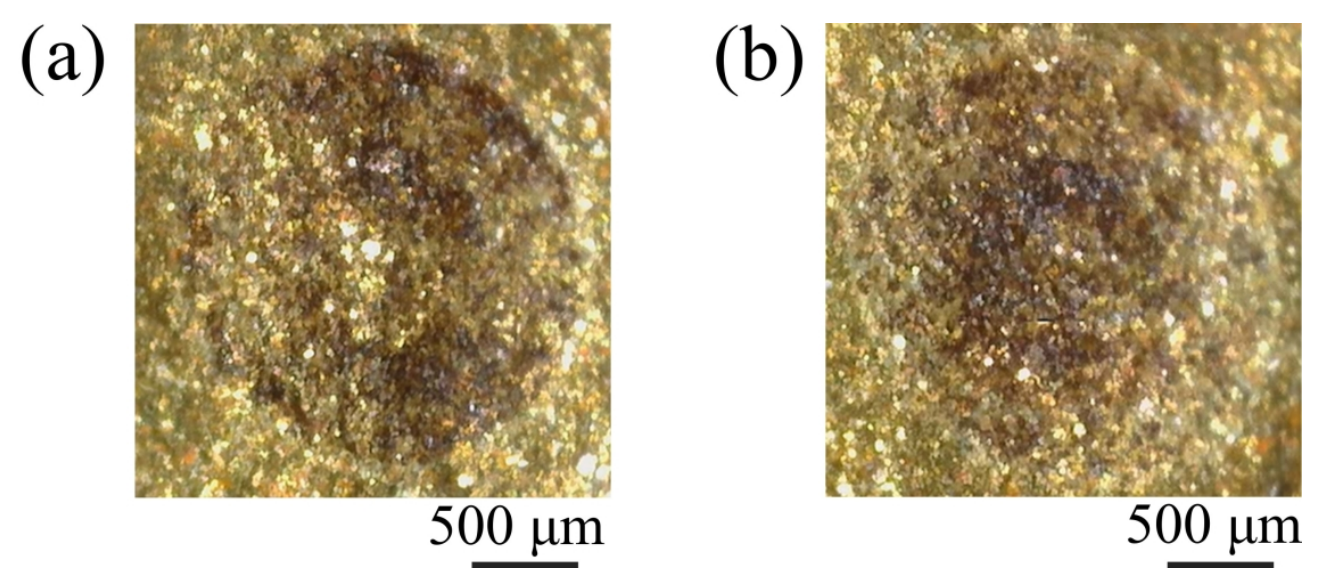

Figure 5 Areas irradiated by 10 laser pulses $\left(1.3 \mathrm{~J} \mathrm{~cm}^{-2} ; 80 \mu \mathrm{s}\right.$ ) at (a) $1 \mathrm{~Hz}$ and (b) $10 \mathrm{~Hz}$ resulted in black particles. The formation of black particles was more evenly distributed in the case of $1 \mathrm{~Hz}$. For $10 \mathrm{~Hz}$, black particles were clustered at the centre of irradiated area.

$$
1091 \times 458 \mathrm{~mm}(72 \times 72 \text { DPI) }
$$




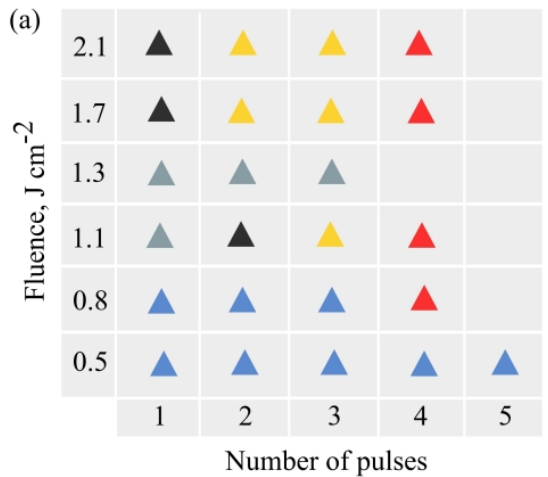

$\begin{array}{ll}\text { Grey residue } & \triangle \text { Water } \\ \begin{array}{l}\text { Grey residue with } \\ \text { black particles }\end{array} & \bigcirc \text { Isopopyl alcohol } \\ \text { Black particles } & \\ \text { Non-discoloured } \\ \text { brass-based overpaint } \\ \text { Exposure of bole } \\ \text { or gesso }\end{array}$
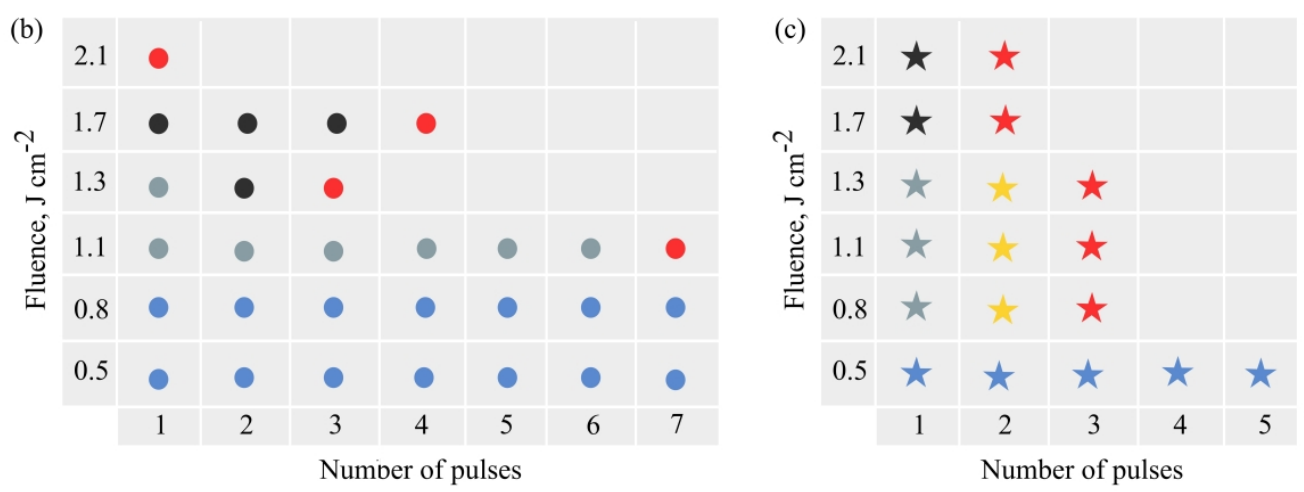

Figure 6 Schematic representation of the effect of fluence and number of pulses exposed to the frame surface which was pre-wetted by (a) water, (b) isopropyl alcohol and (c) acetone.

$1663 \times 1298 \mathrm{~mm}(96 \times 96 \mathrm{DPI})$ 
(a)

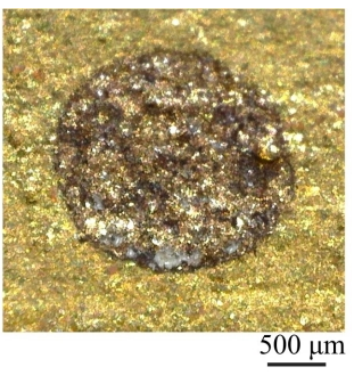

(d)

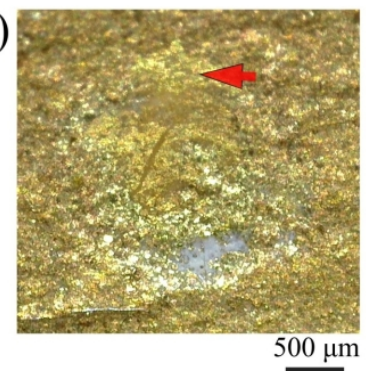

(b)

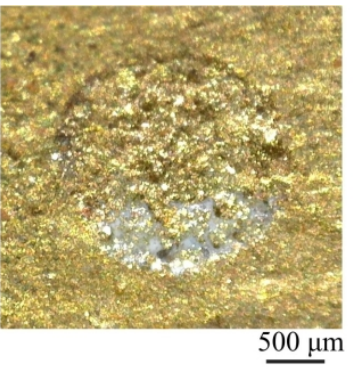

(e)

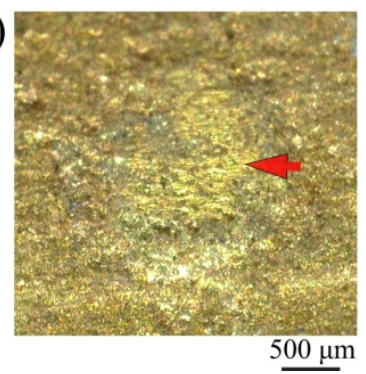

(c)

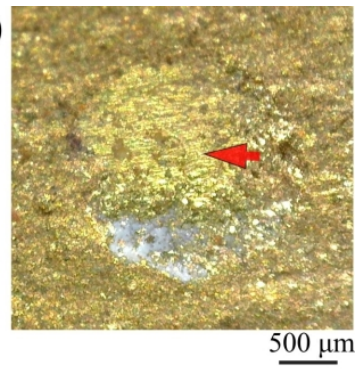

(f)

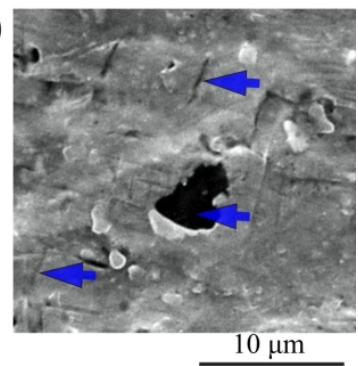

Fig 7 Results obtained from an optical microscope showing the effect of application of acetone as a prewetting and clearing agents with (a-c) 30 , (d) 10 and (e-f) 20 laser pulses $\left(0.8 \mathrm{~J} \mathrm{~cm}^{-2} ; 1 \mathrm{~Hz} ; 80 \mu \mathrm{s}\right)$. Red and blue arrows indicate areas of gold and damage respectively.

$840 \times 494 \mathrm{~mm}(72 \times 72 \mathrm{DPI})$ 
(a)

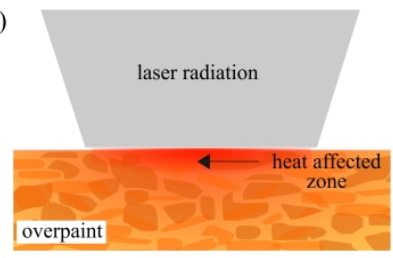

(b)

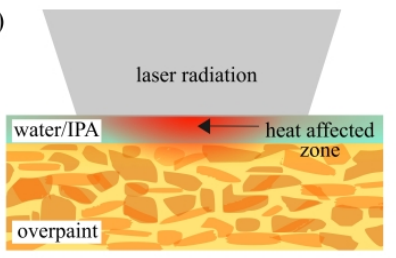

(c)

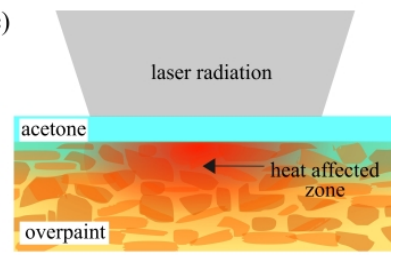

Figure 8 A schematic diagram showing the interaction between Er:YAG laser radiation and (a) a dry overpaint surface, (b) a surface pre-wetted by water or isopropyl alcohol and (c) a surface pre-wetted with acetone. Area in red indicates heat-affected zone.

$2832 \times 708 \mathrm{~mm}(96 \times 96$ DPI $)$ 


\title{
Initial investigation into the effect of varying parameters in using an Er:YAG laser for the removal of brass-based overpaint from an oil- gilded frame
}

\begin{abstract}
The removal of brass-based overpaint, applied during previous restoration, from an oil-gilded frame by the application of solvents can be challenging and difficult to control due to the often similar solubilities of the paint and oil gilding. In this study, Er:YAG laser radiation $(2940 \mathrm{~nm})$ has been used to remove brass-based overpaint from a discoloured overpainted oil-gilded frame. Tests have been systematically carried out to investigate the effect of changes to: (1) laser parameters (fluence; number of pulses; pulse duration; repetition rate), and (2) choice of pre-wetting agent (water; isopropyl alcohol; acetone) on the removal process. Observations of the irradiated surfaces revealed that the thermal interaction between laser radiation and the overpaint led to decomposition of the overpaint binder which weakened the paint sufficiently to enable removal using a cotton swab. By using acetone as a pre-wetting agent, the overpaint was removed from a small area of the frame by 20 pulses at $0.8 \mathrm{Jcm}^{-2}(80 \mu$ s pulse duration; $1 \mathrm{~Hz})$ revealing the gold leaf. This investigation demonstrates the potential for Er:YAG laser radiation in the controlled removal of brass-based overpaint from gilded wood and the requirement for further work to optimise the removal process and characterise the 'cleaned' surface.
\end{abstract}

Keywords: laser cleaning; Er:YAG; gilding; discolouration; overpaint; frame

\section{Introduction}

Gold leaf has a typical thickness of only $0.1-10 \mu \mathrm{m}^{1}$ and gilded surfaces can be easily damaged. Damage can consist of loss of gold and cracking, originating from wear and environmental factors (heat and humidity) or degradation of the underlying materials (gesso and wood). ${ }^{2}$ Deteriorated gold leaf could be 'restored' using brass-based overpaint $^{3}$; a mixture of brass powder and a binder such as oil, resins and cellulose nitrite. ${ }^{4}$ Brass powder became cheaply available when mass production was first introduced in the $1840 \mathrm{~s} .{ }^{5}$ The overpaint was commonly applied to gilded frames in the $20^{\text {th }}$-century during restoration, especially to $19^{\text {th }}$-century paintings. ${ }^{6}$ The brass-based overpaint is often referred to as "bronze" paint. ${ }^{3}$

Although the application of brass-based overpaint is practically and economically convenient, it is considered to be problematic; brass pigments can discolour over time providing an unpleasant darkened surface. ${ }^{7}$ The conventional method of removing the overpaint from gilded objects involves the application of solvents with swab, poultices, solvent gels or emulsions. ${ }^{8}$ Examples of the solvents used to remove the overpaint are acetone, methylated spirits, tri-ammonium citrate, benzyl alcohol and EDTA. ${ }^{6-10}$ Difficulties arise when the overpaint and gilded surface have similar solubilities or polarity indices, e.g. for an oil-based overpaint on an oil-gilded surface. ${ }^{4,8}$ Selective cleaning using a mechanical application of a solvent is then difficult to achieve, i.e. using a solvent which is able to remove the overpaint can lead to the removal of the gold leaf. 
Lasers can be used to deliver energy to surfaces in a very controlled manner. By selecting appropriate laser parameters (wavelength, pulse length, fluence), the thermal interaction (associated with laser pulses at infrared wavelengths) can often be controlled in such a way to facilitate selective removal of unwanted material, such as dirt, unwanted corrosion and paint layers, burial accretions etc., from the surfaces of artworks.

To date the most common laser used for cleaning in conservation has been the $\mathrm{Nd}$ :YAG with a wavelength of $1064 \mathrm{~nm}^{11}$; it has other harmonics of $532 \mathrm{~nm}$ and 266 $\mathrm{nm}$. Regarding gilding conservation, several papers reported the studies of $\mathrm{Nd}: \mathrm{YAG}$ laser cleaning of dirt or soil from gilded surfaces ${ }^{12-15}$, and there were some investigations into the removal of the brass-based overpaint with this type of lasers. $\mathrm{In}^{16}$, it was mentioned that the overpaint cannot be safely removed with solvents while $\mathrm{Nd}$ :YAG irradiation alone led to the complete removal. $\mathrm{In}^{17}$, the irradiation $1064 \mathrm{~nm}$ was able to weaken the adherence between the overpaint and the gold; the overpaint was then able to be removed via mechanical cleaning. In ${ }^{18}$, three Nd:YAG harmonics, 1064 $\mathrm{nm}$ (infrared), $532 \mathrm{~nm}$ (visible) and $266 \mathrm{~nm}$ (uv), were tested on the overpainted sample of gilded wood; it was stated that different wavelengths exhibited different laser-surface interactions.

In this study we use an Er:YAG laser with a wavelength of $2940 \mathrm{~nm}$ as it should provide a different interaction with the overpaint to $\mathrm{Nd}$ :YAG radiation. This wavelength is known to be absorbed strongly by oxygen-hydrogen $(\mathrm{OH})$ and nitrogen-hydrogen $(\mathrm{NH})$ bonds; the absorption of Er:YAG radiation in materials with a high $\mathrm{OH}$ content is confined within a few microns of the surface. ${ }^{19}$ Many of the materials used for overpainting contain $\mathrm{OH}$-bonds, and there have already been studies showing effective removal of shellac ${ }^{20}$, linseed oil ${ }^{21}$ and epoxy resins ${ }^{22}$ using Er:YAG laser radiation.

In a previous study by the authors ${ }^{23}$, preliminary work using an Er:YAG laser was carried out on a neoclassical oil-gilded frame. This study showed that a fluence of $1.2 \mathrm{~J}$ $\mathrm{cm}^{-2}$ fluence (120 $\mu$ s pulse duration) was able to thin brass-based overpaint at a rate of approximately $6.0 \pm 0.5 \mu \mathrm{m}$ per pulse, and that pre-wetting the surface with a thin film of water before irradiation resulted in a slightly lower removal rate of $4.0 \pm 0.5 \mu \mathrm{m}$ per pulse.

The scope of this work was to investigate the effect of: (1) various laser parameters (fluence; pulse duration; number of pulses; repetition rate), and (2) pre-wetting agents (water; isopropyl alcohol; acetone) on the interaction of Er:YAG laser radiation with brass-based overpaint on a previously restored frame. It was decided that a 'real' frame (as opposed to model samples with layers of known composition) would be used in this initial study because naturally aged overpaint should be more representative of the deterioration of other gilded surfaces. A future study will be carried out using artificially aged model samples to gain a more thorough understanding of the processes involved.

\section{Materials and Methods}

All studies were performed on an oil-gilded frame (circa 1900) with brass-based overpaint on the surface. The frame is rectangular $(47.5 \mathrm{~cm} \times 42.0 \mathrm{~cm} \times 4.5 \mathrm{~cm})$, of a neoclassical style, with flattened surfaces on the sides and decorative ornaments at the front (see Fig. 1a).

In a previous study ${ }^{23}$ by the authors, the stratigraphy of the frame was investigated. From the innermost to the outermost layers, the original frame was composed of wood, gesso, yellow bole and gold. The frame had experienced losses of the gold and bole before the application of the brass-based overpaint across the whole frame during a previous restoration. The surface of the frame has become darken due to the 
discolouration of the overpaint which was found to originate from oxides of copper such as $\mathrm{Cu}(\mathrm{I})$ and $\mathrm{Cu}(\mathrm{II})$. Beneath the discoloured surface layer there existed a nondiscoloured overpaint. Fig. $1 \mathrm{~b}$ is a cross-section image taken by an optical microscope at 50x magnification (ZEISS Axio Imager 2) of an area of the frame with losses of gold and bole. The layer of overpaint has a thickness of $20-40 \mu \mathrm{m}$.

The solubility of the frame's materials was tested by gently rolling a swab dampened with solvent across the surface; removal of surface material (as seen on the swab) indicated that the surface is soluble with that solvent. The brass-based overpaint was found to be soluble with acetone, slightly soluble with isopropyl alcohol and insoluble with water.

Fig. 1c and Fig. 1d show test areas $(1 \mathrm{~cm} \times 1 \mathrm{~cm})$ with isopropyl alcohol and acetone. Using isopropyl alcohol, the discolored surface largely unaffected - only small amounts of the discolored paint were removed. Application of acetone led to uneven removal of the discolored overpaint exposing the non-discoloured overpaint beneath; small areas of gesso, indicated by red arrows in Fig. 1d, were also visible from which the paint had been removed completely. Therefore acetone was found to be too aggressive whereas isopropyl alcohol was ineffective. In addition using acetone with a swab led to an uneven removal of the overpaint.

\section{FIGURE_1}

Fig 1 (a) Discoloured brass-based overpaint on the surface of a neoclassical oil-gilded frame.

(b) A cross-section, from an area of the frame without remaining gold leaf showing the overpaint layer with thickness $20-40 \mu \mathrm{m}$. Areas, $1 \mathrm{~cm} \times 1 \mathrm{~cm}$, treated by (c) isopropyl alcohol and (d) acetone. Red arrows indicate small areas of gesso.

An Er:YAG laser system (Lynton Lasers Ltd.) was used as the source of $2940 \mathrm{~nm}$ radiation. Pulse energy can be varied from 20-220 mJ. Pulse duration is dependent upon the pulse energy and is variable between 40 and $120 \mu \mathrm{s}$. Fluence, the radiant energy delivered to the surface per unit area, was deduced by calculating the pulse energy divided by beam size on the surface of the frame. The pulse energy was measured using a power meter (Ophir, Nova P/N 7Z01500). For all experiment the surface of the frame was maintained at $120 \mathrm{~mm}$ from the laser aperture. The laser effective area was calculated, using the $\mathrm{D} 4 \sigma$ diameter definition, to be $2.8 \mathrm{~mm}^{2}$ by assuming that the laser spot is an ellipse; the minor and major axes of the ellipse were measured to be $1.8 \mathrm{~mm}$ and $2.0 \mathrm{~mm}$ via the knife-edge method. Fluence was varied by keeping the beam size constant, while changing the pulse energy by using cover glasses to attenuate the beam. Each cover glass had a thickness $0.17 \mathrm{~mm}$ and attenuated the laser energy by $20 \%$.

The effect of fluence, number of pulses, pulse duration and repetition rate were investigated independently of each other. Three sets of experiments were performed (see Table 1). For all experiments the average laser spot diameter was $1.9 \mathrm{~mm}$ giving an irradiated area on the frame's surface of $2.8 \mathrm{~mm}^{2}$. The surface of the frame was maintained at $120 \mathrm{~mm}$ from the laser aperture. The effects of fluence and number of pulses were studied as shown Set A (Table 1): the surface was irradiated by up to 30 pulses at a range of fluence levels from $0.5-2.1 \mathrm{~J} / \mathrm{cm}^{2}$. This range was selected as it is below the laser damage threshold of an oil-gilded gold surface, $3.3 \mathrm{~J} / \mathrm{cm}^{2}$, as reported in a previous study. ${ }^{23}$ Any loose particles on the surface were cleared by rolling a dry cotton swab gently over the surface after each pulse. The effect of pulse duration was investigated by comparing the results obtained from $\mathrm{A}(80 \mu \mathrm{s})$ and $\mathrm{B}(120 \mu \mathrm{s})$. The effect of repetition rate was investigated by exposing the surface to 10 pulses at 1,5 and $10 \mathrm{~Hz}$. 
The effect of using solvents as a pre-wetting agent was investigated using the parameters from the Set A experiment; a cotton swab dampened with solvent was gently rolled over the surface before irradiation by a single laser pulse. The process was repeated for up to 7 pulses. The solvents tested were de-ionised water, isopropyl alcohol and acetone, which provide a broad range of polarity indices: 10.2, 5.1 and 3.9 respectively.

\section{TABLE_1}

Table 1 Sets of laser parameters used to study the effects of Er:YAG radiation on the surface of an overpainted frame.

The test areas were observed with a portable optical microscope at 90x magnification (Dinolite Premier, AM4113TL). Small specimens collected from tested areas were coated by platinum to study surface topography via scanning electron microscopy (SEM, FEI Quanta 200). The elemental analysis was performed via energy dispersive x-ray spectroscopy (EDX). EDX was also used to confirm the elemental gold on the surface when present. Optical coherence tomography (OCT, Thorlabs GAN620C1) was also used to produce a cross-section image of the different layers of the frame.

\section{Results}

\subsection{Characterisation of surface changes after exposure to Er:YAG laser radiation}

Exposure of the frame's surface to Er:YAG laser radiation resulted in 3 main types of surface appearance depending on the laser parameters used: (1) grey residue: a surface whitish-grey in colour; (2) black particles: dark debris formed on the surface; and (3) non-discoloured overpaint: an area with the colour of brass in a brighter shade than the frame's surface before irradiation. Figs. 2a-c show optical microscopy images of irradiated areas; all were exposed to a single Er:YAG pulse $(80 \mu \mathrm{s})$ at different fluences to present grey residue $\left(0.5 \mathrm{~J} \mathrm{~cm}^{-2}\right)$, black particles $\left(1.1 \mathrm{~J} \mathrm{~cm}^{-2}\right)$ and non-discoloured overpaint $\left(2.1 \mathrm{~J} \mathrm{~cm}^{-2}\right)$.

Fig. $2 \mathrm{~d}$ is a cross-section image obtained by OCT of areas displayed in Fig. 2b. The OCT signal from an untreated area shows an uppermost surface layer indicated by two strong signals at the interfaces separated by approximately 5-10 $\mu \mathrm{m}$. These signals can also be observed throughout the area exposed to an Er:YAG pulse with a grey residue but with uneven separation of 10-30 $\mu \mathrm{m}$; this suggests that the surface has been disrupted creating a rough irregular texture. Fig. $2 \mathrm{e}$ is an OCT image of areas displayed in Fig. $2 b$ showing the formation of black particles above the frame's surface.

\section{FIGURE_2}

Fig 2 Most irradiated area has the appearance of (a) grey residue, (b) black particles and (c) non-discoloured overpaint. Cross-section images obtained from optical coherence tomography (OCT): (d) area of frame exposed to a laser pulse $\left(0.5 \mathrm{~J} \mathrm{~cm}^{-2} ; 80 \mu \mathrm{s}\right)$ showing grey residue; (e) area of frame exposed to a laser pulse $\left(1.1 \mathrm{~J} \mathrm{~cm}^{-2} ; 80 \mu \mathrm{s}\right)$ displaying black particles above the overpaint layer.

Fig. $3 \mathrm{a}-\mathrm{b}$ are secondary electron images obtained via SEM of an area of grey residue (10 pulses; $0.5 \mathrm{~J} \mathrm{~cm}^{-2} ; 80 \mu \mathrm{s} ; 1 \mathrm{~Hz}$ ) showing the rough irregular surface; cavitation bubbles were observed with pores (see Fig. 3b). Fig. 3c shows a 
backscattered electron image obtained via SEM of an area with black particles (1 pulse; $\left.1.3 \mathrm{~J} \mathrm{~cm}^{-2} ; 80 \mu \mathrm{s}\right)$. Flat metal flakes, which have a composition typical of brass (approximate $\mathrm{Cu}: \mathrm{Zn}$ ratio of $84: 16$ ), were observed with various grain sizes up to 80 $\mu \mathrm{m}$. There appears to be a greater proportion of metal flakes in the areas exposed to laser radiation. The matrix lying on the surface in the laser-treated area has a porous texture; there are pores of mostly a few microns in diameter (micro-cavities) and large pores of the order of $10-\mu \mathrm{m}$ diameter.

Fig. 3d, a backscattered electron image, shows an irradiated area (3 pulses; $2.1 \mathrm{~J}$ $\left.\mathrm{cm}^{-2} ; 80 \mu \mathrm{s}\right)$, where stacks of metal flakes observed inside the pore are loosely embedded in a matrix of black particles. The EDX spectrum acquired from black particles (see Fig. 3e) indicates that they mainly composed of carbon and oxygen. The EDX spectrum from a metal flake (see Fig. 3f) shows copper and zinc as the main components.

\section{FIGURE 3}

Fig 3 (a) Boundary between area exposed to 10 pulses of $0.5 \mathrm{~J} \mathrm{~cm}^{-2}(80 \mu \mathrm{s} ; 1 \mathrm{~Hz})$, grey residue, and non-irradiated surface. Area in a blue rectangle (b) shows cavitation bubbles with pores (blue arrows). (c) Boundary between area exposed to 1 pulse of $1.3 \mathrm{~J} \mathrm{~cm}^{-2}$ (80 $\mu \mathrm{s})$ (black particles) and non-irradiated surface; pores (blue arrows), metal flakes (yellow arrows) can be seen. (d) Stacks of brass flakes loosely embedded in a matrix; E and F indicate the location of EDX spot analysis in the matrix and brass flake respectively. (e) EDX spectrum obtained from E (matrix). (f) EDX spectrum obtained from F (brass flake).

\subsection{Effect of laser parameters}

The fluence, number of laser pulses, pulse duration and repetition rate have been found to affect the outcome of irradiating the brass-based overpaint at $2940 \mathrm{~nm}$. The effects of varying these parameters are reported below.

\subsubsection{Fluence and number of laser pulses}

Fig. 4 is a colour grid depicting the appearance of the frame's surface after being exposed to Er:YAG pulses at a range of fluence levels $\left(0.5-2.1 \mathrm{~J} \mathrm{~cm}^{-2}\right) ; 80 \mu \mathrm{s}$ pulse duration; $1 \mathrm{~Hz}$ repetition rate. The lowest investigated fluence $\left(0.5 \mathrm{~J} \mathrm{~cm}^{-2}\right)$ resulted in a grey residue. The area did not show any significant change in appearance as the number of pulses was increased up to 30 . At higher fluences, 0.8 and $1.1 \mathrm{~J} \mathrm{~cm}^{-2}$, the grey residue was observed together with black particles which were difficult to remove with a dry cotton swab. The quantity of black particles increased with the number of laser pulses; gesso and bole were exposed after 4-5 pulses so the surface was not exposed to further pulses. At $1.3 \mathrm{~J} \mathrm{~cm}^{-2}$ black particles covered all of the surface exposed to the laser pulse after the first pulse; this appearance remained unchanged even after 30 pulses. As the fluence was increased to $1.7 \mathrm{~J} \mathrm{~cm}^{-2}$ and $2.1 \mathrm{~J} \mathrm{~cm}^{-2}$, the formation of black particles was observed with the appearance of non-discoloured overpaint. After two pulses, most of the irradiated area appears as non-discoloured overpaint with spots of gesso visible.

\section{FIGURE_4}

Fig 4 (a) Schematic representation of the effect of fluence and number of pulses delivered to the frame surface. (b-e) Images taken from an optical microscope of irradiated areas with laser parameters labelled in (a). Red arrows indicate spots of gesso. 


\subsubsection{Pulse duration}

The formation of grey residue, black particles and the appearance of non-discoloured overpaint, were observed in both investigated cases: $80 \mu \mathrm{s}$ and $120 \mu \mathrm{s}$. However, black particles and non-discoloured overpaint were observed at lower fluence for the shorter pulse duration: $0.8 \mathrm{~J} \mathrm{~cm}^{-2}$ and $2.1 \mathrm{~J} \mathrm{~cm}^{-2}$ respectively for $80 \mu \mathrm{s} ; 1.0 \mathrm{~J} \mathrm{~cm}^{-2}$ and $3.1 \mathrm{~J}$ $\mathrm{cm}^{-2}$ for $120 \mu \mathrm{s}$.

\subsubsection{Repetition rate}

The effect of repetition rate was seen most clearly with the formation of black particles. Fig. 5 shows two areas which were irradiated by 10 pulses at 1 and $10 \mathrm{~Hz}$ at $1.3 \mathrm{~J} \mathrm{~cm}^{-2}$. The distribution of black particles is more uniform at $1 \mathrm{~Hz}$ whereas it appears to be more concentrated near the centre of the area irradiated at $10 \mathrm{~Hz}$.

\section{FIGURE_5}

Fig 5 Areas irradiated by 10 laser pulses $\left(1.3 \mathrm{~J} \mathrm{~cm}^{-2} ; 80 \mu \mathrm{s}\right)$ at (a) $1 \mathrm{~Hz}$ and (b) $10 \mathrm{~Hz}$ resulted in black particles. The formation of black particles was more evenly distributed in the case of $1 \mathrm{~Hz}$. For $10 \mathrm{~Hz}$, black particles were clustered at the centre of irradiated area.

\subsection{Effect of solvents}

Fig. 6 provides a schematic representation of the effect of using different wetting agents combined with Er:YAG laser radiation. The grey residue was observed for all wetting agents after a single pulse at the lowest fluence tested: $0.5 \mathrm{~J} \mathrm{~cm}^{-2}$. The surface appearance did not alter with further pulses (pre-wetting before each pulse).

Black particles and grey residue were seen together after a pulse of $0.8 \mathrm{~J} \mathrm{~cm}^{-2}$ for acetone and $1.1 \mathrm{~J} \mathrm{~cm}^{-2}$ for water and isopropyl alcohol. Above $1.7 \mathrm{~J} \mathrm{~cm}^{-2}$, a single laser pulse resulted in the appearance of black particles for all wetting agents. Continued application of solvent and additional laser pulses transformed the surfaces with black particles into those with non-discoloured overpaint, bole or gesso. The most pronounced change in appearance occurred when using acetone as a pre-wetting agent; gesso was seen after only 3 pulses at $0.8-1.3 \mathrm{~J} \mathrm{~cm}^{-2}$ and 2 pulses at $1.7-2.1 \mathrm{~J} \mathrm{~cm}^{-2}$.

Since pre-wetting the surface with acetone before the irradiation provided the most pronounced change, further tests were carried out using acetone as a pre-wetting agent and using a swab dampened with acetone to clear the surface after a set of laser pulses $\left(0.5-2.1 \mathrm{~J} \mathrm{~cm}^{-2} ; 1 \mathrm{~Hz} ; 80 \mu \mathrm{s}\right)$. In all cases black particles were produced, with the quantity increasing with fluence and number of pulses. The black particles were able to be completely cleared from the surface using a cotton swab dampened with acetone, uncovering the layers beneath.

Figs. $7 \mathrm{a}-\mathrm{c}$ provide an example of a test area treated with 30 laser pulses at $0.8 \mathrm{~J}$ $\mathrm{cm}^{-2}$. Black particles were observed after irradiation (Fig. 7a) before being removed by a gentle application of acetone, leaving an area of exposed gesso and a rough surface of non-discoloured overpaint (Fig. 7b). Further clearing with acetone without more laser pulses revealed a surface of gold leaf as shown in Fig. 7c. This was confirmed by SEMEDX. It was discovered that the overpaint was easier to remove using acetone once the surface had been disrupted by exposure to laser pulses.

When using 10 pulses (Fig. 7d) gold leaf was uncovered; areas of bole and gesso were also exposed. After 20 pulses (Fig. 7e) gold leaf was observed without any visible 
damage when viewed under an optical microscope (up to 95x magnification). SEM observations (imaging with secondary electrons), Fig. 7f, revealed small areas within the cleaned area without gold and scratches (a few microns) when observed at $1573 \mathrm{x}$ magnification. It was unclear that the losses of gold were due to the cleaning or they resided on the original gilded surface before being overpainted. The scratches are highly unlikely to be a result of the laser-surface interaction.

\section{FIGURE_6}

Fig 6 Schematic representation of the effect of fluence and number of pulses exposed to the frame surface which was pre-wetted by (a) water, (b) isopropyl alcohol and (c) acetone.

\section{FIGURE_7}

Fig 7 Results obtained from an optical microscope showing the effect of application of acetone as a pre-wetting and clearing agents with $(\mathrm{a}-\mathrm{c}) 30$, (d) 10 and (e-f) 20 laser pulses $\left(0.8 \mathrm{~J} \mathrm{~cm}^{-2} ; 1 \mathrm{~Hz} ; 80 \mu \mathrm{s}\right)$. Red and blue arrows indicate areas of gold and damage respectively.

\section{Discussion}

Er:YAG laser radiation at $2940 \mathrm{~nm}$ is highly absorbed by materials containing hydroxyl groups $(\mathrm{OH})$ such as water. The Er:YAG photon energy is only $0.4 \mathrm{eV}$, which is insufficient to disassociate the hydroxyl radical, so interaction with an OH-containing substance is likely to be thermal rather than chemical. For example, a hydroxyl bond in a water molecule requires a disassociation energy of $4.8 \mathrm{eV}$ on average. ${ }^{24}$ The photon energy does however match the vibrational excitation energy of the hydroxyl-containing compounds ${ }^{25}$, and so absorption of these photons and subsequent non-radiative deexcitation leads to the production of heat. ${ }^{26}$ The main interaction between Er:YAG radiation with the frame's surface is therefore most likely to be photothermal. If no wetting agent is used, the laser energy is transferred to the overpaint, resulting in a rapid temperature increase (within the timescale of the individual laser pulse) and subsequent vaporisation of volatile components.

With increasing fluence the surface appearance changes from a grey residue, to black particles and finally to non-discoloured overpaint. The grey residue is a rough irregular surface which has a colour of whitish-grey. The surface with grey residue did not change in appearance when being irradiated by more laser pulses at a constant fluence. This is similar to the result found $\mathrm{in}^{27}$; oil-based varnish rather withstood Er:YAG laser radiation and the roughness of irradiated surface was increased.

The pores seen in the cavitation bubbles (Fig. 3a) are believed to originate from jetting of volatiles or steam production. ${ }^{28}$ With further extraction of volatiles the paint binder undergo carbonization via pyrolysis resulting in amorphous porous carbon or char ${ }^{29}$ observed as black particles. The explosive exclusion of volatiles leads to the ejection of chars and discoloured brass powders leaving a surface comprising decomposed paint binder and loosely-bound brass powders (see Fig. 3c). Consequently, the layers beneath such as non-oxidised overpaint, bole or gesso are revealed. At higher fluence bole or gesso were observed after fewer pulses; this suggested that the temperature at the surface is higher with increased fluence.

At a longer pulse duration the surface appearance changes at a higher fluence e.g. black particles, which resulted from the decomposition of the binding medium, occurred at $0.8 \mathrm{Jcm}^{-2}$ for a $80 \mu \mathrm{s}$ pulse and at $1.0 \mathrm{Jcm}^{-2}$ for a $120 \mu$ s pulse. This is because a longer 
pulse allows more time for heat to diffuse deeper into the material. ${ }^{30}$ In contrast, for a shorter pulse heating is confined nearer the surface resulting in a higher temperature rise. At higher repetition rate black particles were formed near the centre. This is because there is less time between pulses for heat to conduct away, and the rate of heat conduction is faster near the edge as compared to the centre of the irradiated area.

When using solvent pre-wetting of the surface combined with Er:YAG laser radiation, the interaction is also thermal but the mechanism of heat transfer is different for $\mathrm{OH}$ containing and $\mathrm{OH}$-free solvents. Water contains $\mathrm{OH}$ so it absorbs the radiation directly and heat is generated as a consequence. If the water layer is sufficiently thin (less than a few microns), heat can then diffuse from the water film to the surface of the frame. The paint binder and varnish are soluble in isopropyl alcohol and acetone. These solvents may thus permeate into the layers beneath. ${ }^{6}$ In addition, application of the solvent via a gentle roll of a cotton swab can remove material from the surface.

Fig. 8 is a schematic diagram indicating the heat-affected zone produced by the absorption of Er:YAG laser radiation. A dry surface without any pre-wetting absorbs laser radiation producing the heat where the laser was targeted. Isopropyl alcohol, which contains $\mathrm{OH}$, is heated by direct absorption of the laser radiation; heat can then diffuse to the overpaint provided the alcohol film is sufficiently thin. Acetone contains no $\mathrm{OH}$ so it is transparent at $2940 \mu \mathrm{m}$; the overpaint directly absorbs the laser radiation leading to the production of heat in the overpaint layer. Therefore, the heating of the overpaint is more efficient when pre-wetting the surface with acetone in comparison to water and isopropyl alcohol. Although minimal laser radiation is absorbed by the acetone, a proportion of the heat generated in the overpaint is transferred to the acetone from the overpaint.

The tested solvents have different specific heat capacities: $2.2 \mathrm{~J} \mathrm{~g}^{-1} \mathrm{C}^{-1}$ (acetone), $2.7 \mathrm{~J} \mathrm{~g}^{-1}{ }^{\circ} \mathrm{C}^{-1}$ (isopropyl alcohol) and $4.2 \mathrm{~J} \mathrm{~g}^{-1} \mathrm{C}^{-1}$ (water). It would require $2.2 \mathrm{~J}$ for $1 \mathrm{~g}$ of acetone to raise its temperature by $1{ }^{\circ} \mathrm{C}$; whereas $2.7 \mathrm{~J}$ and $4.2 \mathrm{~J}$ are needed for isopropyl alcohol and water. The solvents also differ in boiling point: $56{ }^{\circ} \mathrm{C}$ (acetone), $82.5{ }^{\circ} \mathrm{C}$ (isopropyl alcohol) and $100{ }^{\circ} \mathrm{C}$ (water). Therefore, when being heated via the diffusion of heat from the overpaint, the temperature of the acetone rises faster and vaporises easier than the other solvents. Explosive evaporation of the solvent leads to particle ejection and/or weakening of the paint layer. The quick vaporisation of acetone explains why a lower fluence is required to form black particles and why gesso was seen after fewer pulses than for the other solvents tested.

\section{FIGURE_8}

Fig. 8 A schematic diagram showing the interaction between Er:YAG laser radiation and (a) a dry overpaint surface, (b) a surface pre-wetted by water or isopropyl alcohol and (c) a surface pre-wetted with acetone. Area in red indicates heat-affected zone.

\section{Conclusion}

Removing discoloured brass-based overpaint, applied during previous restoration, from a gilded surface is a challenge especially when the overpaint and the gold leaf layer have similar solubility. A conventional treatment of solvent alone could risk damaging the gold leaf. This study intended to investigate the effect of some Er:YAG laser parameters on the interaction of laser radiation at $2940 \mathrm{~nm}$ with an overpainted oilgilded frame. The frame's surface was systematically exposed to Er:YAG laser radiation with different parameters: fluence $\left(0.5-2.1 \mathrm{~J} \mathrm{~cm}^{-2}\right)$, pulse duration (80 and 120 
$\mu \mathrm{s})$, repetition rate $(1-10 \mathrm{~Hz})$; and the effect of using pre-wetting agents: water, isopropyl alcohol and acetone was investigated.

Observations made by optical microscopy and scanning electron microscopy have revealed that the interaction between laser radiation and the frame's surface is via a thermal effect in which heat is generated at a target surface. Irradiating a discoloured overpainted surface at increasing fluence resulted in the appearance of a grey residue at low fluence, black particles and non-discoloured overpaint at higher fluence.

The grey residue and black particles originated from the paint binder undergoing vaporisation and carbonisation. The binding medium decomposed into black particles at $0.8 \mathrm{Jcm}^{-2}$ for a $80 \mu$ s pulse and at $1.0 \mathrm{Jcm}^{-2}$ for a $120 \mu$ s pulse. Decomposition of the binder weakened the paint sufficiently to enable removal with a cotton swab and, consequently, non-discoloured overpaint was revealed. Bole and gesso were exposed with an increasing number of laser pulses i.e. $4-5$ pulses for 0.8 and $1.0 \mathrm{Jcm}^{-2}$ and 2 pulses for the fluence above $1.3 \mathrm{~J} \mathrm{~cm}^{-2}$.

The use of acetone as a pre-wetting agent prior to irradiation (and acetone to clear the 'weakened' material after irradiation) led to decomposition and removal of the overpaint at a lower fluence than with the use of isopropyl alcohol or de-ionised water or without the use of a wetting agent. Possible mechanisms for the laser-material interaction have been proposed for the different cases. Using acetone as the pre-wetting and clearing agent, the discoloured brass-based overpaint was removed from a small area of the frame and gold leaf was revealed after 20 laser pulses at $0.8 \mathrm{~J} \mathrm{~cm}^{-2}(80 \mu \mathrm{s}$ pulse duration; $1 \mathrm{~Hz}$ ). Complete removal of the overpaint using either ErYAG laser radiation alone or acetone alone was not possible without significant loss of gold leaf.

The results of this initial investigation demonstrate the potential for Er:YAG laser radiation in the controlled removal of discoloured brass-based overpaint from an oilgilded frame when combined with the use of solvents. Further work is required to (1) optimise the removal process; (2) characterise the state of the 'cleaned' surface. Tests will be carried out on artificially aged mock-up samples of known composition and stratigraphy.

\section{References}

[1] Evelyne Darque-Ceretti, Eric Felder, and Marc Aucouturier, 'Foil and Leaf Gilding on Cultural Artifacts; Forming and Adhesion', Matéria (Rio de Janeiro) 16 (January 2011): 540-559.

[2] Moses Jenkins, 'INFORM guide: information for historic building owners. Gilding Techniques, Care and Maintenance', Gilding Techniques, Care and Maintenance (January 2007): 1-8.

[3] Holly McGowan-Jackson, 'Frames conservation in Australia and GOCSIG: Reflections on the Past and Thoughts for the Future', Paintings Conservation in Australia from the Nineteenth Century to the Present: Connecting the Past to the Future (Canberra: AICCM, 2008), 173-181.

[4] Shayne Rivers and Nick Umney, 'Conservation of Furniture' (Oxford: Butterworth-Heinemann, 2003), 773.

[5] Jonathan Thornton, 'A Brief History and Review of the Early Practice and Materials of Gap-Filling in the West', Journal of the American Institute for Conservation 37, no. 1 (1998): 3-22.

[6] Malgorzata Sawicki, 'The Visit of the Queen of Sheba to King Solomon by Edward Poynter, 1884-1890. The Frame Revisited', AICCM Bulletin 25, no. 1 
(2000): 21-32.

[7] Malgorzata Sawicki, 'Practical Implications of Research into Non-traditional Ingilding Techniques: Loss Compensation in Conservation of Gilded Objects', AICCM Bulletin 30, no. 1 (2006): 63-69.

[8] Malgorzata Sawicki et al., 'An Investigation of the Feasibility of the Use of Gels and Emulsions in Cleaning of Gilded Wooden Surfaces. Part A: Removal of Brass-Based Overpainting', Heritage Wood. Cultural Heritage Science, ed. Nevin A., Sawicki M. (2019): 1-36.

[9] Arlen Heginbotham, 'The Examination and Treatment of an American Gilded Girandole, ca. 1830' (Postprints of the Wooden Artifacts Group presented at the AIC 27th annual meeting, St. Louis, June 1999).

[10] Malgorzata Sawicki, 'From 'Lady in Black' to 'Art Students': The Story Behind Changing a Frame', AICCM Bulletin 30, no. 1 (2006): 44-50.

[11] Beth Graue, Sigrid Brinkmann, and Casparus Johan R. Verbeek, 'Laser Cleaning of Ancient Egyptian Wall Paintings and Painted Stone Surfaces', Lasers in the Conservation of Artworks VIII (London: CRC Press, 2011), 53-58.

[12] Malgorzata Sawicki, Victoria Bramwell-Davis, and Barbara Dabrowa, 'Laser cleaning from a practical perspective: Cleaning tests of varied gilded-wood surfaces using Nd:YAG Compact Phoenix laser system' AICCM Bulletin 32, no. 1 (2011): 44-53.

[13] Malgorzata Sawicki et al., 'An Investigation of the Feasibility of the Use of Gels and Emulsions in Cleaning of Gilded Wooden Surfaces. Part B:Cleaning of Soiled Oil-gilded', Heritage Wood. Cultural Heritage Science, ed. Nevin A., Sawicki M. (Cham: Springer, 2019), 37-64.

[14] Michael Panzner et al, 'Laser Cleaning of Gildings', Lasers in the Conservation of Artworks VI (Heidelberg: Springer, 2007), 21-28.

[15] Auxiliadora Gómez-Morón et al., 'A study on the effect of 1064 nm Nd-YAG laser cleaning of gilded wood supports' Conserving Cultural Heritage (2018): 21-23.

[16] Marek Strzelec et al., 'Overpaint Removal on a Gilded Wooden Bas-Relief Using a Nd:YAG Laser at $1.064 \mu \mathrm{m}$ ', Lasers in the Conservation of Artworks $V$ (Heidelberg: Springer, 2005), 133-138.

[17] Joakim Striber, Vanja Jovanović, and Maja Jovanović, 'Easel paintings on canvas and panel: application of Nd:YAG laser at $355 \mathrm{~nm}, 1064 \mathrm{~nm}$ and UV, IR and visible light for the development of new methodologies in conservation', Lasers in the Conservation of Artworks XI (Toruń: NCU Press, 2017), 279-292.

[18] Pedro Gaspara et al., 'A study of the effect of the wavelength in the Q-switched Nd:YAG laser cleaning of gilded wood', Journal of Cultural Heritage 1, no. 2 (2000): 133-144.

[19] Adele DeCruz, Joseph A. Izatt, and Derek Nankivil, 'On the use of OCT to examine the varnish layer of paintings cleaned with an Er:YAG laser', Photonics, Optics and Laser Technology 2016 (IEEE, 2016).

[20] Jana Striova et al., 'Optical and spectroscopic tools for evaluating Er:YAG laser removal of shellac varnish', Studies in Conservation 60, (2015): 91-96.

[21] Jana Striova et al., 'Free-running Er:YAG Laser Cleaning of Mural Painting Specimens Treated with Linseed Oil, "Beverone" and Paraloid B72', in Lasers in the 
Conservation of Artworks VIII (London: CRC Press, 2011), 85-91.

[22] Stefanie Scheerer, Meg Abraham, and Odile Madden, 'Study of the Effects of Laser Radiation on Epoxy Resins and Epoxy Systems on Stone, Ceramic, and Glass Surfaces', Journal of Cultural Heritage 4, (2003): 223-229.

[23] AUTHOR'S PREVIOUS STUDY HAS BEEN REMOVED IN THE ANONYMIZED FILE

[24] David L. Nelson, Albert L. Lehninger, and Michael M. Cox, Lehninger Principles of Biochemistry (New York: W. H. Freeman, 2005).

[25] Christoph Menzel, Klaus Dreisewerd, Stefan Berkenkamp, and Franz Hillenkamp, 'The Role of the Laser Pulse Duration in Infrared Matrix-assisted Laser Desorption/ionization Mass Spectrometry', Journal of the American Society for Mass Spectrometry 13, no. 8 (2002): 975-984.

[26] Mohammad A. Omary and Howard H. Patterson, 'Luminescence, Theory', in Encyclopedia of Spectroscopy and Spectrometry, 3rd ed. (Oxford: Academic Press, 2017), 636-653.

[27] Alessia Andreotti et al., 'Novel Applications of the Er:YAG Laser Cleaning of Old Paintings', in Lasers in the Conservation of Artworks VI (Berlin, Heidelberg: Springer, 2011), 239-247.

[28] Alfred Vogel, Emil Brujan, Peter Schmidt, and Kester Nahen, 'Interaction of Laser-Produced Cavitation Bubbles with Elastic Boundaries', in IUTAM Symposium on Free Surface Flows. Fluid Mechanics and Its Applications 62 (Dordrecht: Springer, 2001), 327-335.

[29] Harry Marsh and Francisco Rodríguez-Reinoso, 'Production and Reference Material', in Activated Carbon (Oxford: Elsevier Science, 2006), 454-508.

[30] Shadi M. Karazi, Inam U. Ahad, and K.Y. Benyounis, 'Laser Micromachining for Transparent Materials', in Reference Module in Materials Science and Materials Engineering (Netherlands: Elsevier BV, 2017) 